\title{
Effect of Herds' Activities on Sediment Yields in a Watershed
}

\author{
Abdulkareem Ibrahim Ayinla ${ }^{1^{*}}$ \\ ${ }^{1}$ Department of Agricultural \&Bio-Environmental \\ Engineering, \\ Kaduna Polytechnic, Kaduna, Nigeria
}

\author{
Jonah C. Agunwamba ${ }^{2}$ \\ ${ }^{2}$ Department of Civil Engineering, \\ University of Nigeria, Nsukka, Nigeria.
}

Abstract: The activities of herds' has created several migratory pathways, fetching leaves of the trees, trapping on both water and ground surfaces, the effects that has resulted into loss of natural vegetation cover, intensification of erosion and desert encroachment. This is believed to contribute to silt and clay particle formations, hence, sediment increase. It is therefore, the aim of this research to investigate the effect and provide a model for use to overcome the limitations of the use of USLE in an area of herds' columns. Soil samples were collected along the column routes for particle size analysis using Bouyoucos method, while during the rainfall event, water sample mixtures were collected for analysis of Suspended Sediment Concentrations using filtration and drying methods. The sediment load was obtained by multiplying the discharge and suspended concentration, and then converted to kilogram per day/tones per day. A rating relationship between the sediment loads and herds' indices was used to determine the sediment discharge characteristics. In modeling the effect, Multivariate Universal Soil Loss Equation (USLE) was employed. The rainfall erosivity index of USLE (EI I30 ) was calculated from the product of total Kinetic Energy of rainfall event and its maximum 30-mm intensity. The Soil erodibility indices derived from herds' column were regressed with measured sediments to determine the extent and severity of soil structure trapping, detaching and grinding actions, as impacts of herds' on the catchment. Validation of the model was done using data that were not from the data used for the model formulation. The results revealed the soil structures of the catchment as unstable and prone to sediment and erosion wash because of continuous and extensive animal herdship. The model predicted well with effect of herds' using Modified Clay Ratio having highest coefficient of determination, $R^{2}=0.83$ with coefficient of correlation, $R=0.91$ at $0.01(p<0.01)$ confidence level. The drainage area revealed coefficient of determination, $R^{2}$ and coefficient of correlation, $R$ values of 0.013 and 0.11 at 0.01 level of significant, respectively. The model reasonably matched with the observed data and moderately predicted with herds' activities, and then recommended the use of the model for predicting sediment yields in any watershed with high number of herds among others compared.

Key Words: Herds', Columns, Sediments, Yields, And Watershed

\section{INTRODUCTION}

Fulltime cattle breeders are the pastoral Fulani that practices transhumance and herd-splitting on daily basis, and are not involved in major cropping and trading activities. The name Fulani has become synonymous with grazing and cattle ownership with regard to their transit attitudes in Africa. The movement over the years has led to a pastoral calendar in which the location and the grazing habits of the herds can be predicted on catchment basis of sediments production and generation. Herds' and pastoralists engaged in extensive pastoral movements which are vary according to individual circumstances, dictated by the seasonal distribution of grass and water. The pastoralists moved to avoid harmful insects, abominable weather, livestock thieves, tax assessors, and hostile social environment $[1,2]$.

Adopting several migratory pathways, the pastoralists were able to graze extensively along the routes, fetching the leaves of the trees in an area of little or no grass to feed their herds; littering the environment with cattle dugs, trapping on both surface of ground and water sources. It is evidence that a migrating herds' comprising of several family units move in a column of up to five meters wide and two kilometers long of which the period of column passes a given point, trembling, breaking and trapping soil structure [3, 4]. The effects of this activities result in insufficient grazing areas, overstocking of existing lands, loss of natural vegetation cover and intensification of erosion and desert encroachment with logical end of being another Sahel of their migratory routes.

The management method is regarded as extensive and free-ranging grazing with massive reliance on social goods and the range land for folder which can be classified as short and long distance. Walking in the life of herds' accounted for about one quarter of herding time, whereas resting and watering together represent only $5 \%$ of total time, while actual grazing time accounted for approximately $75 \%$ [5]. Free-ranging animals show a peak of grazing activity in the early morning, another in the late afternoon and substantial grazing during night. Night grazing account for about $25 \%$ of the total daily grazing time in free-ranging indigenous cattle, while most of the time that the cattle are not in grazing field they are on the move $[6,7]$.

The distributions of herds in Nigeria as reported by [8] follow more conventional divisions of naisseur, the breeding areas in the North: engraisseur, the fattening areas in the middle; and consommateur, the consumption areas in the South. On like a nature where livestock are distributed according to the vegetation and agro climatic zone, where semi-desert is for camel zone; semi-arid is for the cattle zone and sub-humid is for the goat zone. 
Resource Inventory Management data as reported by [9] suggested that livestock population is either static or declined due to the emigration of Nigeria herdsmen. The official livestock population figures were indirectly and extrapolated from various administrative sources, including jangali cattle tax receipts, vaccination returns, slaughter records, trade movements and exports, though should be treated with caution, because of uncertainties in the data [3]. The total estimated cattle population in Nigeria as at 2004 was 15.986million made-up of indigenous breeds of Bunaji (white Fulani), Sokoto and Adamawa Gudali as the major breeds [10], but till date no official record.

The production of sediment and its transportation is highly depends on the magnitude of the various active and passive forces operating within the watershed. Over areas of continental and subcontinent scale, the major determinants of sediment yield of watersheds are climate and relief [11]. In local areas, additional and often important controls include geology [12], soil types [13, 14], vegetation [15], drainage characteristics [16, 17], time [18, 19] and land use pattern within the drainage basin [20, 21]. Among all these research no one have studied or included in their works the effect and contribution of herds' activities on the catchment basis.

In predicting and estimating sediment yields, many authors have used Universal Soil Loss Equation (USLE) for instant, [22, 23, 24, 25], among all, no one has related herds' activities in their formulation. Activities of herds' have ability to detaching, breaking and grinding of soil structure of a catchment even to the extent of deforestation (especially during dry season), and believed to contribute to silt and clay particle formations, leaving the land to reduction in resistivity to erosion (soil erodibility). The catchment peculiar with favorable environment for green pastures, water, and conductive climate are liable to this condition and, hence, abode large population column of herds'.

Therefore, the aim of this study is to provide a model for use to overcome the limitations of the use of USLE in an area where cattle population density is high, and assumed to be relevant in sediment yielding and loading in a catchment.

\subsection{Site Location}

Kangimi earth dam reservoir was constructed across Kangimi River approximately $3.22 \mathrm{~km}$ upstream of its confluence with Kaduna River covers a watershed area of about $224 \mathrm{~km}^{2}$. It lies in the Savanna region, between latitude $10^{\circ} 46^{\prime} \mathrm{N}$ and longitude $7^{\circ} 25^{\prime} \mathrm{E}$. The reservoir has a total volume of $59,789,001 \mathrm{~m}^{3}$ of water and covered surface area of about $12 \mathrm{~km}^{2}$ with about $9.63 \mathrm{~km}$ in length and a maximum depth of $12.92 \mathrm{~m}$. The catchment housed about $62.3 \%$ of cattle range in central part of Nigeria in the Northern part of the country as shown in Fig. 1.

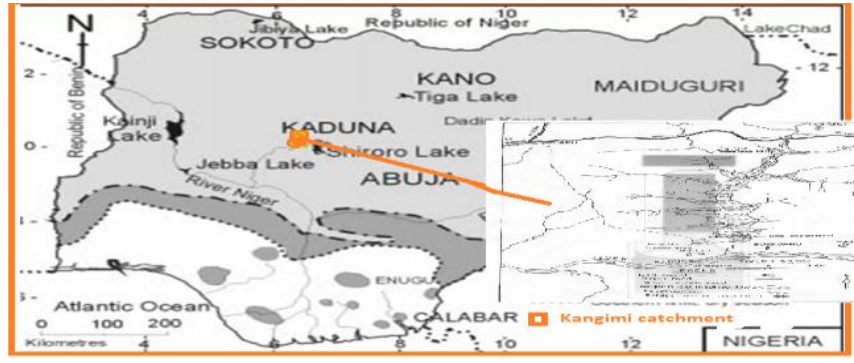

Fig. 1: Herds' distribution in Nigeria and Kangimi Catchment location

\subsection{Data Sampling Techniques and Data Collection}

An area within the catchment of Kangimi where herds' column activities were pronounced was selected for data collection. Soil samples were collected along the routes at the depth of $20 \mathrm{~cm}$ randomly at $50 \mathrm{~m}$ interval, for particle size analysis.

Water and sediment samples were collected by grabbing and trapping method after 3minutes predetermined time as minimum time recommended [26]. The volume of the mixtures collected at this 3minutes time were measured and recorded as discharge, Q. Grabbing and trapping methods [22] were adopted because of the simplicity, cost effective, and that water and sediment materials are collected at one time, and can also be easily related to catchment feature characteristics.

\subsection{Laboratory Analysis}

The soil samples were analysed for particles size distribution using Bouyoucos Hydrometer method. The amounts of particles size distribution dictated the susceptibility indices of the soil of the catchment. The soil organic matter was estimated by wet digestion method [27] values obtained were multiplied by 1.729 to derive the percentage soil organic matter.

The suspended sediment concentration, $\mathrm{C}_{\mathrm{s}}$, was determined from the mixtures of the water and sediment samples in the laboratory. The samples were shaken thoroughly after which $250 \mathrm{ml}$ standard quantity was obtained and filtered through Whitman filter paper. The sediment as residuals in the filter was oven-dried at $105^{\circ} \mathrm{C}$ for 18 hours and then cooled and re-weighed. Meanwhile, the Whitman filter paper weight has been earlier recorded. The difference between the initial weight of the filter paper and the final weight constitutes the suspended sediment concentration, $C_{S}$.

For conversion to $\mathrm{mg} / \mathrm{l}$, the residual weight is multiplied by 4 since the filtered sample has a volume of $250 \mathrm{ml}$ ( $1 / 4$ of a litre). The value obtained constitutes the suspended sediment load for a sample. The value is then multiplied with the caught volume of the mixtures for preset time of 3 minutes, to derive the suspended sediment discharge in milligrams per second when converted to meter cubic per second.

The soil erodibility indices were measured using dispersion ratio proposed by Middleton reported in [28]; 
Critical level of soil organic matter [29]; Modified clay ratio [30] and Clay ratio [31].

\subsection{Estimation of Suspended Sediment Load (SSL)}

For the estimation of SSL, temporal extrapolation was required to have a reasonable prediction as reported in [18] and [32]. The condition is usually achieved through the relationship between suspended sediment concentrations, suspended sediment load (SSL) to catchment runoff discharge, based on a limited number of sediment.

Thus, SSL $Q_{S S L}(\mathrm{mg} / \mathrm{s})$ was given as a product of discharge and concentration and then converted to $\mathrm{kg} /$ day and tons/day, respectively as

$$
\begin{aligned}
Q_{S S L} & =\frac{Q C_{S}}{1000} \times 60 \times 60 \times 24(\mathrm{Kg} / \text { day }) \\
Q_{S S L} & =\frac{Q C_{S} \times 60 \times 60 \times 24}{1000 \times 1000} \quad(\text { Tons } / \text { day })
\end{aligned}
$$

Where, $Q_{S S L} \quad=$ Suspended Sediment Load in $(\mathrm{Kg} /$ day $)$ and (Tons/day), respectively; $Q=$ flow discharge in $\mathrm{m}^{3} / \mathrm{s}$; and $C_{s}=$ Suspended Sediment concentration in $\mathrm{mg} / \mathrm{s}$

The continuous record of suspended sediment discharges provided the estimation of sediment yield throughout the year for each of the catchment [33].

\subsection{Relating Sediment Loads with Herds' Activities}

Sediment-Rating curves have been widely employed by many authors, for instance, [34], [35], and [25]. The empirical relation between surface water discharge and sediment concentration or sediment discharge can be expressed graphically as a single relationship. The curve is usually developed using logarithmic transformation data with surface water discharge as independent variable and sediment concentration as the dependent variable. The curve relation is defined by power function [36]

$$
S S_{Q}=a Q^{b}
$$

Where, $S S_{Q}$ is the suspended sediment yields, $\mathrm{kg} / \mathrm{s}$; tons/day; $Q$ is the surface water discharge, $\mathrm{m}^{3} / \mathrm{sec}$; and $a, b$, are the intercept and slope gradient respectively.

The solution to the function can be solved using linear model of logarithmic transformation

$$
\log S S_{Q}=b \log Q+\log a
$$

\subsection{Herds' Activities and its Effect}

This phenomenon can be explained using USL equation given by [37]

$$
\mathrm{A}=(\mathrm{R} \cdot \mathrm{K} \cdot \mathrm{L} \cdot \mathrm{S} \cdot \mathrm{C} \cdot \mathrm{P})
$$

Where, $\mathrm{A}$ is Expected annual soil loss (tones/ha/year); $\mathrm{R}$ is Rainfall erosivity in (MJ $\mathrm{mm} / \mathrm{ha} / \mathrm{h} /$ year); $\mathrm{L}$ and $\mathrm{S}$ is Topographic factors (dimensionless), respectively; $\mathrm{K}$ is Soil erodibility in ( $\mathrm{Mg}$ ha $\mathrm{h} / \mathrm{ha} / \mathrm{MJ} / \mathrm{mm}$ ); C and $\mathrm{P}$ is Cover-management practices and support practices factors that describe land use, respectively.
For this study, drainage area, $\left(A_{d}\right)$ and Herds' density, $\left(H_{d}\right)$ were substituted into USL equation to predict herds' effect on sediment yields. Thus,

$$
S S_{Q}=\left(\text { R.K.L.S.C.P.A } A_{d} \cdot H_{d}\right)
$$

Database preparation for Land Use/Land Cover Detection were obtained using global positioning satellite (GPS) to capture the coordinate points around the relevant positions. This served as the basis data for topography map, and for generating influencing variables such as length, elevations, slopes, and catchment areas. Enhanced Thematic Mapper (EMT+) at a resolution of $30 \mathrm{~m}$ of June 2016 imagery was used and the satellite data covering study area were obtained from Global Land Cover Facility (GLCF) (http://glcfapp.glcf.umd.edu:8080/esdi/) and Earth Explorer site (http://earthexplorer.usgs.gov/).

\subsection{Rainfall Erosivity $(R)$}

Rainfall data of 20years (1995 - 2015) was collected from Nigeria Meteorological Station. The R-factor was taken as product of the Kinetic energy of a rainfall event $(\mathrm{KE})$ and its maximum $30-\mathrm{mm}$ intensity $\left(I_{30}\right)$ given by [38]

$$
R=\frac{1}{n} \sum_{j=1}^{n} \sum_{k=1}^{m}\left(E I_{30}\right)
$$

Where, $\mathrm{R}$ is average monthly rainfall erosivity; $\mathrm{n}$ is the number of years recorded; $m, j$ is the number of erosive events during a given month, $j ; E I_{30}$ is the rainfall erosivity index of a single event $k$. The erosivity of a single event $E I_{30}$ is given by [39]

$$
\left.E I_{30}=\left(\sum_{r=1}^{m} K E\left(V_{e}\right)\right) I_{30}\right)
$$

Where, $K E$ is the rainfall kinetic energy, and $V_{e}$ is the rainfall volume $(\mathrm{mm})$ during the period of storm that is divided into $m$-parts. The rainfall $K E$ per rainfall depth $(\mathrm{mm})$ and per unit area (ha) for each time interval is calculated from [38]

$$
K E=0.29\left(1-0.72 e^{-0.05 I_{r}}\right)
$$

Where, $I_{r}$ is the rainfall intensity during the time interval $(\mathrm{mm} / \mathrm{hr})$.

\subsection{Soil Erodibility factor $(K)$}

The soil erodibility factor, $K$, represents both susceptibility of soil to erosion and the amount and rate of runoff [40]. Soil erodibility factor of dispersion ratio by [28] was used.

\subsection{Slope Length factor $(L)$}

Reference [41] presented the relationship to compute the slope length factor, $\mathrm{L}$ of the catchment as

$$
L=\left(\frac{l}{22.1}\right)^{m}
$$

Where, $l$ is the field slope length $(\mathrm{m}) ; m$ depends on slope steepness which is equivalent to 0.5 for slopes of 3 $4 \%$; 0.3 for slopes between $1-3 \%$ and 0.2 for slopes less than $1 \%$ [41]. 


\subsection{Slope Steepness factor $(S)$}

For the slope length longer than $4 \mathrm{~m}$, reference [40] recommended the slope steepness factor as

$$
\begin{gathered}
S=10.8 \operatorname{Sin} \theta-0.03(\text { For slope gradient } \leq 9 \%) \\
S=10.8 \operatorname{Sin} \theta+0.03(\text { For slope gradient } \geq 9 \%)
\end{gathered}
$$

Where, $\theta$ is slope angle of the catchment in degree.

\subsection{Land Used Practices $(P)$ and Cover Practices $(C)$}

A unit for Land use practice will be considered as no conservation practices observed, and mostly recommended by many authors. For the $\mathrm{C}$ factor, European Soil Bureau recommended

$$
C=e^{-\alpha\left(\frac{N D V I}{\beta-N D V I}\right)}
$$

Where, NDVI is Normalized Difference Vegetation Index. The parameters $\alpha, \beta$ are 2 and 1 , respectively, assigned to give reasonable results as suggested by [42].

\subsection{Drainage area $\left(A_{d}\right)$}

The Pacific Southwest Inter-Agency Committee procedure of area classification that gives each drainage basin characteristics of a subjective numerical rating was employed. This work conducted collection of the suspended sediment concentration during storm events for the individual sub-catchment classifications. Empirical equation of power function (3) was developed strictly as a function of drainage area based on catchment basin sediment survey, drainage area, $A_{d}$ as independent variable and sediment concentration as dependent variable.

\subsection{Herds' Variable $\left(H_{d}\right)$}

To measure the variable, three indices values were proposed and tested to determine the extent and severity of effect, and then used the index that best gives coefficient of correlation, and regressed as linear and $\log$ exponent function to sediment load.

\subsection{Regression method of modeling}

A simple regression model was developed for prediction of sediment load [43, 44]. In a standard of regression modeling, two variables called independent variable $(\mathrm{X})$ and dependent variable $(\mathrm{Y})$ are correlated. The variable to be forecasted (dependable variable) is expressed as a mathematical function of the independent variable. The analysis can be done by computer, while the expected regression equations were either: Linear, Power, Natural logarithms, and Polynomial functions.

\subsection{Model Verification}

The measured sediment yields data were randomly selected and does not include previous used for the model development or previously used elsewhere, and removed from the compiled dataset and used as a validation dataset. Sediment yields were predicted using the model and compared to the measured sediment yields from the test database. A comparison of the predicted sediment yields to the measured sediment yields was used to evaluate the model, and also, the predicted strength of the model developed was compared to those of previously published models using an independent set of measured sediment yields retained from the complied data.

\subsection{Soil Particles Size}

Generally, the average soil particle size distribution indicated mean percentage range of silt plus clay of $34.46 \%$ to $75.13 \%$ while sand range is $33.05 \%$ to $65.54 \%$. The average organic matter $(\mathrm{OM})$ is between $2.89 \%$ to $4.67 \%$, the condition that defined the soil catchment as moderate in term of OM. Soil erodibility indices derived from soil physical properties includes CR with the average values range of 1.63 to 4.08 (high by the standard). The soils having DR $>0.15$ is said to be high, hence, the results indicated average range values of 0.71 to 0.1 .54 (very high). The CLOM average values range is 0.037 to 0.109 , while MCR average values ranged from 1.36 to 3.57 . These results suggested that, the soil erodibility of the study area is high, making the catchment unstable and could face the risk of soil surface wash.

\subsection{Catchment Topography and Digital Elevation Model (DEM) Maps}

Figure $2(\mathrm{a} \& \mathrm{~b})$ presents the topography and digital elevation model (DEM). The figure presents the basis of catchment feature characteristics available in Kangimi catchment setup.

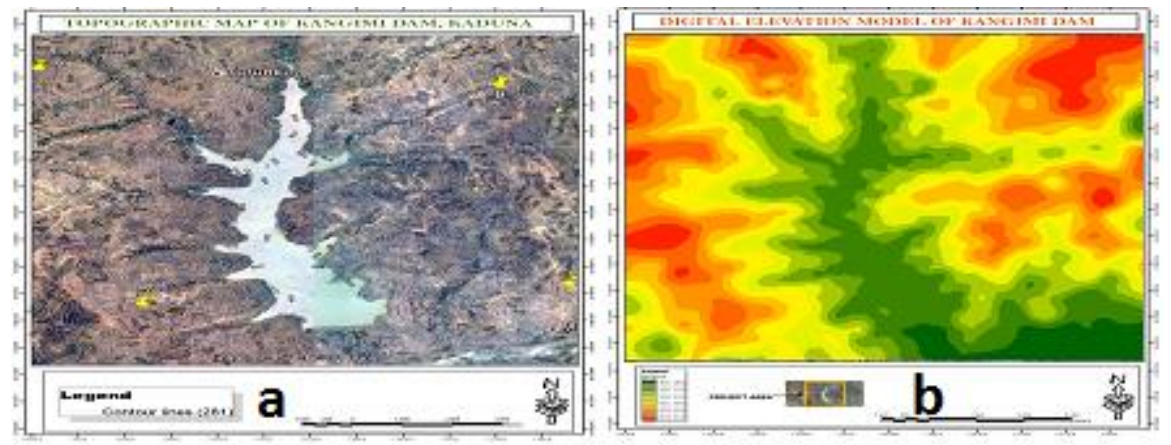

Fig. 2 (a \& b): (a). Topography and (b). Digital Elevation Model Map 


\subsection{Extracted Drainage Parameters values}

Ten (10) major distributaries were identified and the drainage features were presented in Table 1.0 as derived from topography and DEM maps in Fig. 2 (a \& b).

Table 1.0: Estimated values of drainage features

\begin{tabular}{|c|c|c|c|c|c|c|c|c|c|}
\hline $\begin{array}{l}\text { Sub- } \\
\text { Catchment }\end{array}$ & $\begin{array}{l}\text { Length } \\
\text { (m) }\end{array}$ & Area $\left(m^{2}\right)$ & $\begin{array}{l}\text { Max. } \\
\text { Height( } \\
\text { m) }\end{array}$ & $\begin{array}{l}\text { Mini } \\
\text { height(m }\end{array}$ & $\begin{array}{l}\text { Change in } \\
\text { Elevat } \\
\text { (m) }\end{array}$ & $\begin{array}{l}\text { Drainage } \\
\text { Density }\end{array}$ & $\begin{array}{l}\text { Relief } \\
\text { Ratio }\end{array}$ & $\begin{array}{l}\text { Slope } \\
\text { Length } \\
\text { Fact. L }\end{array}$ & $\begin{array}{l}\text { Slope Grad. } \\
\text { (degree) }\end{array}$ \\
\hline Loko Koro & 2700 & 1590594.23 & 624 & 613 & 11 & 0.0017 & 0.004 & 11.05 & 1.88 \\
\hline Loko Ali & 2190 & 929934.50 & 640 & 611 & 29 & 0.0024 & 0.013 & 9.95 & 2.05 \\
\hline Balbela & 2400 & 1075922.18 & 643 & 608 & 35 & 0.0022 & 0.015 & 10.42 & 4.29 \\
\hline Bahago & 3500 & 4208315.95 & 653 & 609 & 44 & 0.0008 & 0.013 & 12.58 & 4.16 \\
\hline Kangimi Main & 7900 & 16593262.74 & 644 & 607 & 37 & 0.0005 & 0.005 & 18.91 & 4.01 \\
\hline R/Kurmin & & & & & & & & & \\
\hline Zaria & 5500 & 7475734.78 & 616 & 609 & 7 & 0.0007 & 0.001 & 15.78 & 1.12 \\
\hline Jagiwa & 5900 & 3062416.13 & 647 & 615 & 32 & 0.0019 & 0.005 & 16.34 & 3.41 \\
\hline Hadamshi & 4300 & 1544647.78 & 653 & 614 & 39 & 0.0028 & 0.009 & 13.95 & 3.89 \\
\hline Gora & 8300 & 1322987.30 & 644 & 613 & 31 & 0.0063 & 0.004 & 19.38 & 3.37 \\
\hline Danyaro & 2300 & 216701.31 & 643 & 611 & 32 & 0.0106 & 0.014 & 10.2 & 3.12 \\
\hline
\end{tabular}

\subsection{Land Cover Practices, $C$}

Table 2.0 presents six classifications according to land use with $\mathrm{C}$ values on the catchment

TABLE 2.0: Land cover and respective C-factor

\begin{tabular}{cccc} 
Land use & Area Covered $\left(\mathbf{m}^{\mathbf{2}}\right)$ & Percentage $(\%)$ & C-factor \\
\hline Vegetation & $156,514,099.0000$ & 59.570 & 0.7669 \\
Farm land & $38,972,195.0000$ & 14.833 & 0.1153 \\
Waterbody & $27,789,988.0000$ & 10.577 & 0.0001 \\
Bare land & $15,110,165.0000$ & 5.751 & -0.0593 \\
Unclassified & $14,203,713.0000$ & 5.406 & 0.0150 \\
Settlement & $10,149,638.0000$ & 3.863 & 0.0118 \\
Total & $262,739,800.0000$ & 100 & \\
\hline
\end{tabular}

Vegetation area is higher than that of farm land probably because the crops have not grown to full size to cover the farm land as vegetation does. It has been earlier reported that NDVI increases as rainfall increases [22] so crops progressively follow the pattern of rainfall distributions.

\subsection{Rainfall erosivity factor}

The estimated $\mathrm{R}$ factor values range from 1627.81 to $717.17 \mathrm{MJ} / \mathrm{mm} \mathrm{ha}^{-1} \mathrm{hr}^{-1} \mathrm{year}^{-1}$, while the mean value is 1082.06 $\mathrm{MJ} / \mathrm{mm} \mathrm{ha}^{-1} \mathrm{hr}^{-1} \mathrm{year}^{-1}$. This result indicated that the rainfall was high throughout the period of analysis.

\subsection{Drainage area and Sediment load relationship}

As observed in Fig. 2 (a), a large proportion of the sub-catchment areas within the catchment are located in areas $<1,000,000 ; 2,000,000-3,000,000 ; 3,000,000-4,000,000 ; 4,000,000-5,000,000 ; 5,000,000-6,000,000 ;$ and $>6,000,000$. The grouped of sub-catchment for the entire catchment were identified to contain seven data points, though must be treated with caution. Specific sediment load versus drainage area grouped was regressed for linear relationship and log exponent. The linear and $\log$ plots were illustrated in Figs. 3 (a \& b). 


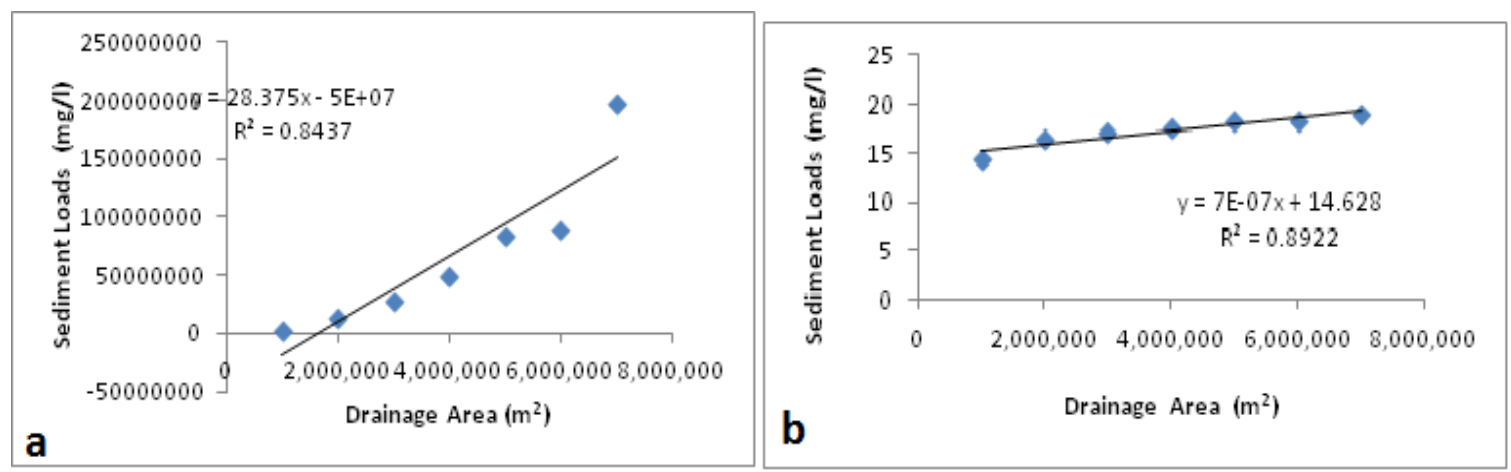

Fig. 3: (a) Linear and (b) LOG relationships between drainage area and sediment loads

The coefficients of the drainage area and sediment loads relationship indicated that there is a direct relationship between drainage area and sediment loads for the catchment as exhibited in figure $\mathrm{C}(\mathrm{a} \& \mathrm{~b})$. In order to check for the significance of the regression coefficients, intercept and slope, output, the ANOVA test was conducted and was observed to be statistically significant $(0.003)$ at 0.05 level of significance.

The coefficient of correlation, $\mathrm{R}$ and coefficient of determination, $\mathrm{R}^{2}$ was high, though the values are high, the inference of the values cannot be made without checking the statistical significance of the $\mathrm{R}^{2}$ computed. Since the value of $\mathrm{R}^{2}$ is high, it can be concluded that the independent variable (drainage area) is a good determinant of the dependent variable (sediment load).

In the same way, the log exponent summarized that there is a direct relationship between drainage area and sediment loads for the catchment as demonstrated in figures.
In order to check for the significance of the regression coefficients too, the ANOVA test was conducted and was observed to be statistically significant $(0.001)$ at 0.05 significant level. Therefore, it can be said that there is a strong relationship between the regression coefficients.

The t-statistic test under the conditions for $\log$ analysis indicated, $\mathrm{R}=0.92, \mathrm{t}^{*}=5.21, \mathrm{p}=0.11, \mathrm{t}(0.025,7)=$ 2.37, while $\log$ indicated $\mathrm{R}=0.95, \mathrm{t}^{*}=1.46, \mathrm{p}=0.000$. The results suggested that $\log$ exponential model is statistically significant at 0.01 level of significance and will be accepted to build the proposed model.

\subsection{Herds' route impacts on sediment yields}

In order to derive the sediment loads from the herds' impact on the catchment, the instantaneous suspended sediment loads was regressed against soil erodibility indices derived from the herds' route using linear and log exponent. The linear plots in Figs. 4 (a, b, c) present the results.

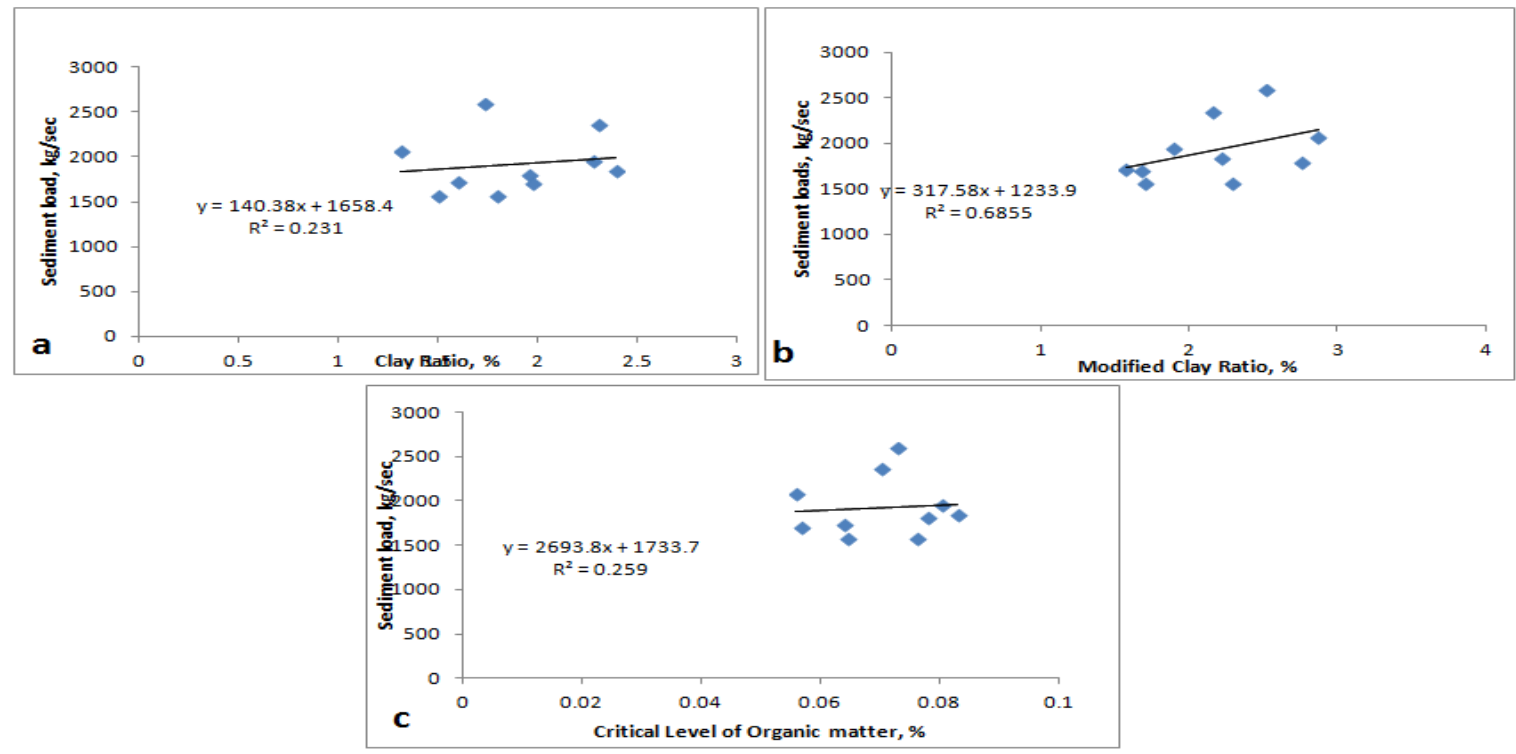

Fig. 4 (a, b, c): Scatter plot relationships of (a) Modified Clay; (b) Clay Ratios; (c) CLOM and sediment loads

The coefficient of determination, $\mathrm{R}^{2}$ in figures were weak, though it is not enough to conclude. Correlation and multiple regression analysis were used to further determine the relationships. The linear results show that MCR as herds' impact indicated R-value of $0.43, \mathrm{n}=10, \mathrm{p}=0.04, \mathrm{t}^{*}=$ $1.35, \mathrm{t}_{(0.025,9)}=2.23$, while $\mathrm{CR}$ indicated $\mathrm{R}=0.15, \mathrm{n}=10, \mathrm{p}=$ $0.03, \mathrm{t}^{*}=0.44, \mathrm{t}_{(0.025,9)}=2.23$ and CLOM shown $\mathrm{R}=0.77, \mathrm{n}=$
$10, \mathrm{p}=0.08, \mathrm{t}^{*}=0.22, \mathrm{t}_{(0.025,9)}=2.23$. The results suggested that there is statistical significant between the sediment discharge and all the indices since $\mathrm{t}^{*}$ is less than $\mathrm{t}_{(0.025,9)}$ at 0.05 significance level excluding CLOM with $\mathrm{p}=0.08$.

The log indicated that MCR has $\mathrm{R}=0.46, \mathrm{n}=10, \mathrm{p}=$ $0.000, \mathrm{t}^{*}=1.46, \mathrm{t}_{(0.025,9)}=2.23$; $\mathrm{CR}$ with $\mathrm{R}=0.16, \mathrm{n}=10, \mathrm{p}=$ $0.000, \mathrm{t}^{*}=0.45, \mathrm{t}_{(0.025,9)}=2.23$; and CLOM with $\mathrm{R}=0.09, \mathrm{n}=$ 
$10, \mathrm{p}=0.0001, \mathrm{t}^{*}=0.25, \mathrm{t}_{(0.025,9)}=2.23$. The results indicated that all the indices were statistically significant at 0.01 level of significance, though one is stronger than another, MCR is stronger and will be consider for proposed model.

\subsection{Model Development}

The multivariate model was development from the USL equation and presented as thus
$\operatorname{LogSS}_{Q}=\log (399.06)+\log (14.63)+(6.75 E-$ $\left.07 \log A_{d}\right)+\log (7.474)+(0.152 \log M C R)$

(14)

\subsection{Model Calibration and Evaluation}

The model is calibrated using measured data from the catchment. The predicted and observed data were plotted as shown in Figs. 5 (a, b, c)
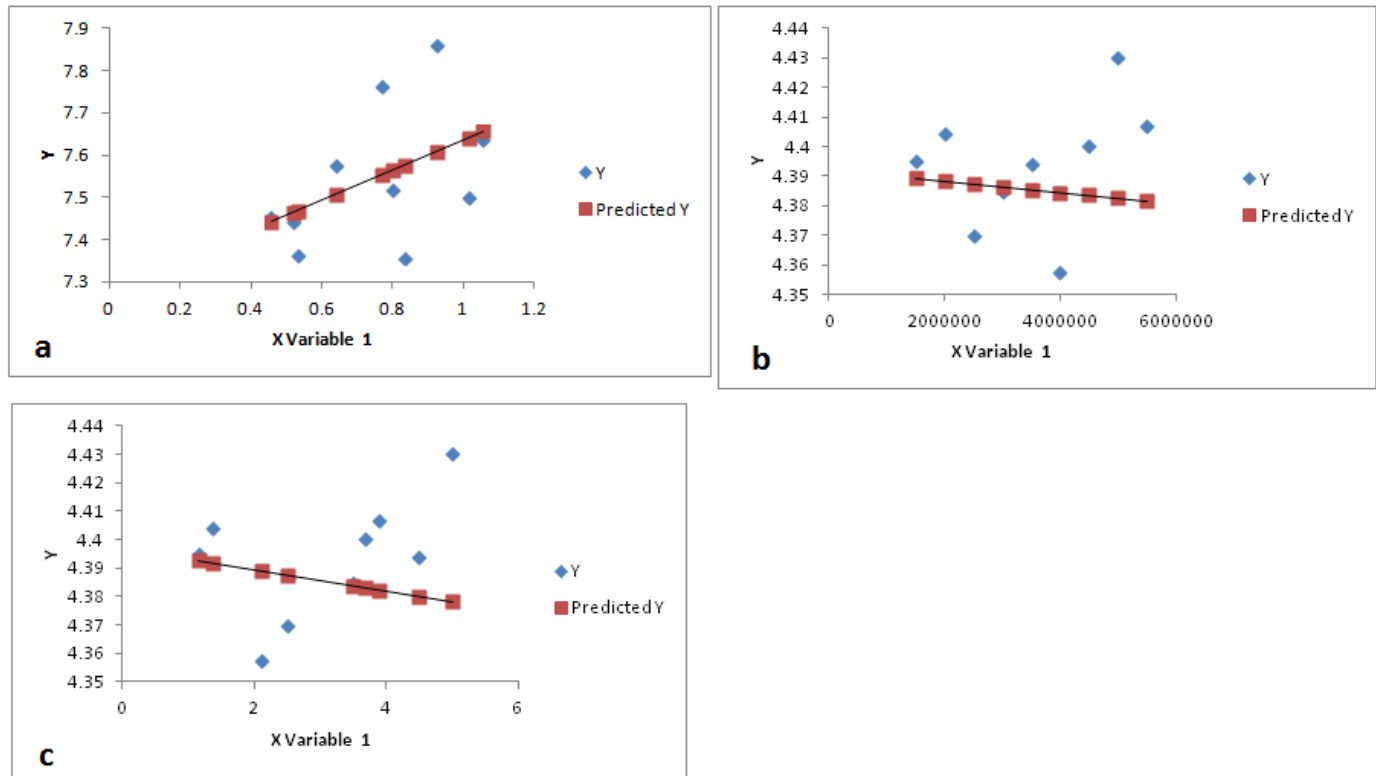

Figs. 5: Predicted sediment yields on the effect of (a) Herds' activities, (b) Drainage Area, and (c) Slope

The model positively predicted well with the effect of herds' using MCR as the coefficient of determination, $\mathrm{R}^{2}$ and coefficient of correlation, $\mathrm{R}$ indicated 0.83 and 0.91 , respectively at $\mathrm{p}=0.000$ (confidence level of 0.01 ). The partial plot of the variables as predicted in Fig. 5a shows the positive linear trends between the independent and dependent variable that moderately predicted within the measured data. 


\subsection{Comparison and Assessment of The Models}

Figures $6(\mathrm{a}, \mathrm{b}, \mathrm{c})$ present the predicted graphical results of developed model and existing ones
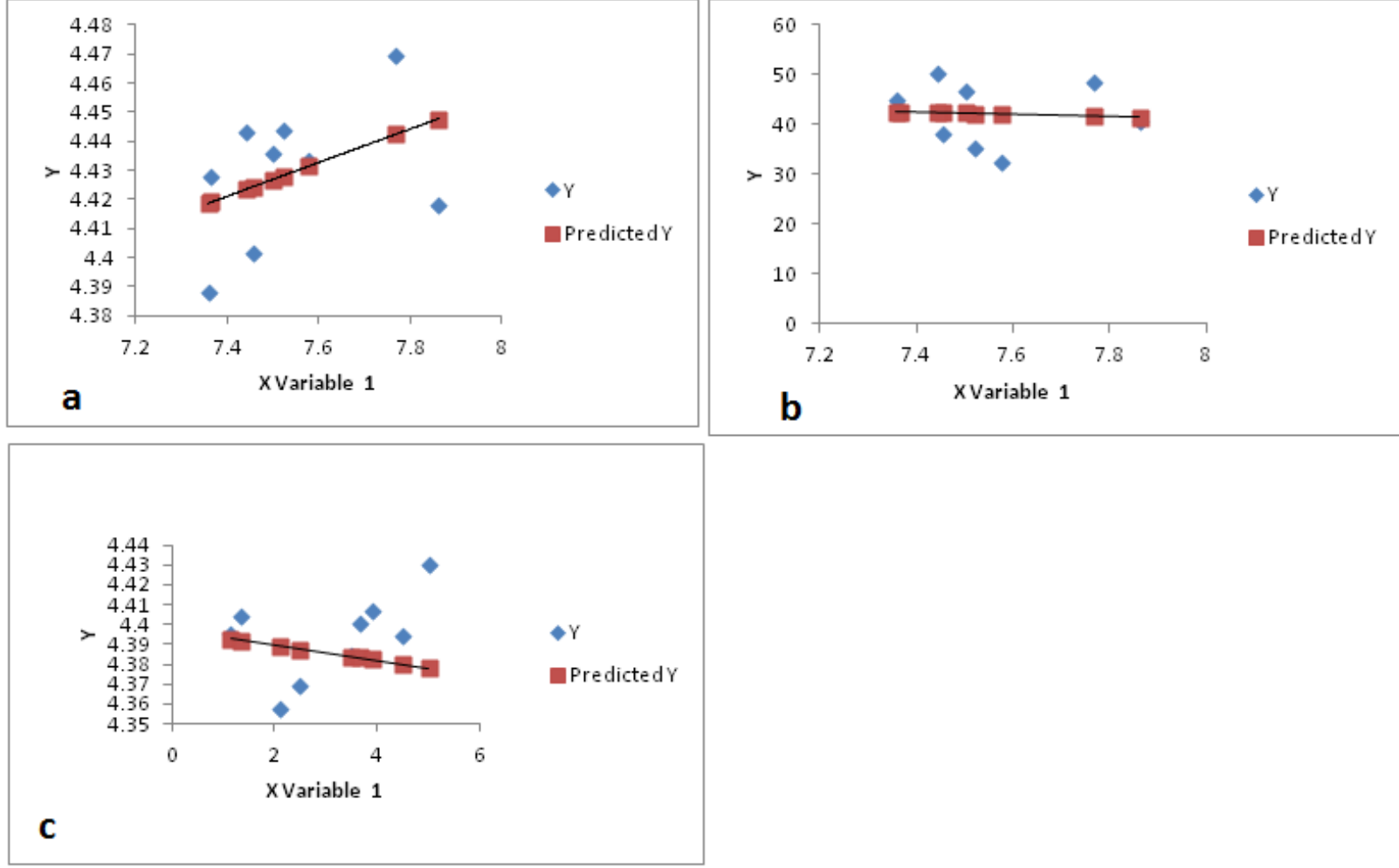

Fig. 6: Graphical (a) Owned (b) Gartner et al. (2008) and Flaxman (1974) Models output comparison with measured data

Generally speaking, the developed model will perform best in the study catchment than the two compared models. The model shows coefficient of determination, $\mathrm{R}^{2}=0.67$, while the coefficient of correlation, $\mathrm{R}=0.71$, $\mathrm{p}=0.000(1.14 \mathrm{E}-05)$ meaning that the result is statistically significant at 0.01 level of significance. Looking at Fig. 6a, the model predictions is moderately predicted and remain within the measured data, this is an echo of the strength of the model over the compared ones.

Reference [45] model prediction suggest a weak coefficient of determination, $\mathrm{R}^{2}$ as value indicated 0.004 and correlation, $\mathrm{R}=0.06, \mathrm{p}=0.58(\mathrm{p}>0.05)$. While, the Flaxman (1974) model predicted statistical values $R^{2}=0.05, R=0.23$, though, the model is weak for the study catchment, but it is statistically significant at $0.01,(p=1.22 \mathrm{E}-14)$.

This study used information on the herds' activities assumed to lead to soil breaking, and grinding as major variable using USL equation parameters to develop and predict potential sediment yields model of the KDR catchment in Kaduna State, Nigeria. The model was evaluated using coefficient of determination $\mathrm{R}^{2}$, coefficient of correlation, $\mathrm{R}$, t-test and partial plots, using a test dataset not used to develop the model, the variable was found to have physical relationship with sediment yield.

The developed model demonstrates a good predictive capacity with effect of herds' column. The coefficient of determination, $\mathrm{R}^{2}=0.67$ and coefficient of correlation, $\mathrm{R}=$ 0.71 , at 0.001 level of significance $(p=1.14 \mathrm{E}-15)$. However, the effect demonstrated that a valuable contribution of the variable (Herds' column) to the sediment yields in the catchment is very significant, and again the severity of soil structural stability due to breaking, and grinding as demonstrated in soil particle size analysis with high silt plus clay is a supportive argument.

\subsection{Conclusion}

The soil particle analysis generally revealed that the soil texture of the catchment is mostly sandy-clay and sandy-clay-loam, found to be unstable and likely prone to sediment and erosion wash probably due to herds' activities and other conditions as a result of soil structure breaking and grinding. The increasing impact of animal rearing, in the catchment together will seriously aggravate sediment wash and erosion risk in the catchment as results indicated a significant level. The model result reasonably matched with the observed data and moderately predicted within the data. However, herds' variable was highly significant and very good indication of its contribution to the production of sediment materials in the catchment. Among the models considered and compared with, the model performed better and could be recommended for predicting and estimating sediment yields from the KDR catchment, which also have advantage to overcome the deficiency of USLE in herds' column areas.

\subsection{Recommendation}

The KDR catchment as a whole has a huge capability to store sediment and buffer the effects of increasing 
sediment supply due to environmental conduciveness and herds' adaptive. The study originally initiated and developed this model using herds' column as variable for the purpose of KDR catchment sediment yields prediction, it is necessary to intensify the studies.

The outcome model here is empirical and therefore do not necessarily account for all of the factors that may also adversely affect the catchment sediment yields.

The study recommended the model to be use for estimating and predicting sediment yields at KDR catchment level and adjacent or neighbouring catchments.

\section{REFERENCE}

[1] P. C Salzman, J.G. Galaty, D. Aronson, and A. Chouinard, "Future of Pastoral People". Proceedings of a Conference held in Nairobi, Kenya 4-8 ${ }^{\text {th }}$ August, 1980.

[2] M. Awogbade, "Fulani Pastoralism: Jos case study, Zaria", Ahmadu Bello Press. www.gamji.com/fulani_references. 1983

[3] W. Fricke, "Cattle husbandry in Nigeria: a study of its ecological conditions and social-geographical differentiations", Heidelberger Geographischen Arbeiten, Heft 52. Germany, Geographisches Institut der Universitat Heidelberg, 1979

[4] R. Vengroff, "Upper Volta: Environmental uncertainty and livestock production" Texas: n.p. www.gamji.com/fulani_references., 1980.

[5] B. Wolfgang, "Agropastoral herding practices and grazing behavior of cattle in the Sub-humid zone of Nigeria". 1998, www.ilri.org/infoServ/Webpub/fulldocs/..

[6] C. A. Smith, "Studies on the Northern Rhodesia Hyparrhenia veld1: The grazing behavior of indigeneous cattle grazed at light and heavy stocking rates". J. Agric. Sc. (Camb.) 1959, 52:369-375.

[7] R. J. Haggar, "Grazing behavior of Fulani cattle at Shika, Nigeria". Trop. Agric. (Trinidad)., 1968, 45:179-185.

[8] M. Horowitz, "Research priority in pastoral Societies: An agenda for the 1980s". "In the future of pastoral people Proceedings of a Conference held in Nairobi, by the Institute of Development Studies. 1980, Pp 61-88.

[9] O. Bourn, W. Wint, R. Blench, and E. Woolley, "Nigeria Livestock Resources Survey". www.fao.org/WAICENT/... 1990.

[10] P. O. Okaiyeto, I. R. Mohammad, S.O. Lamidi, and A.A. Abubakar, "The structures and marketing of Beef cattle in Katsina State of Nig”. J. of Eng. and Applied Sc., 2009, 1(2):125-129.

[11] J. P. Syvistki, M, S. D. Peckhan, R. Hilberman and T. Mulder, "Predicting the Terrestrial Flux of Sediment to the Global Ocean: Planetary Perspective. Sedimentation Geology", 2003, 162, pp. 5-24.

[12] S. M. Mclennan, "Weathering and global denudation". J. of Geology, 1993, 101, pp.295-303.

[13] W. H. Wischmeier, and D. D. Smith, "Predicting rainfall erosion losses- A guide to conservation planning". U.S. Department of Agriculture Handbook, 537, Washington, DC., 1978

[14] J. O. Bartholic, "Predicting Sediment Delivery Ratio in Saginaw Bay Watershed. Institute of Water Research, Michigan State University, East Lansing, M I., 2004.

[15] J. M. L Jansen and R. B. Painter, "Predicting sediment yield from climate and topography", J. of Hydrology, 1974, 21, pp. 371-380.

[16] P. Pinet and M. Sourau, "Continental erosion and large-scale relief”. Tectonics, 1988, 7, pp. 563-582.
[17] J. D. Milliman and J. P. M. Syvitski, "Geomorphic/tectonic control of sediment discharge to the ocean: The importance of small mountaneous rivers". J. of Geology, 1992, 100, 525544.

[18] K. J. Gregory and D. E. Walling, "Drainage Basin Form and Processes: A Geomorphological Approach". London: Edward Arnold Publishers Ltd., 1973, 456 pp.

[19] S. A. Schumm, "The Fluvial System" London: John Wiley and Sons. 1977.

[20] G. L. Morris and J. Fan, "Reservoir sedimentation handbook". McGraw-Hill, New York, 1998

[21] G. Verstraeten and J. Poesen, "Factors Controlling Sediment Yield from Small Intensively Cultivated Catchments in a Temperate Humid Climate". Geomorphology, 2001, 40, pp.123-144.

[22] L. Xixi, "Soil erosion and sediment yield in the upper Yangtze, China", Durham theses, Durham University, 1998. Available at Durham E-Theses Online: http://etheses.dur.ac.uk/4645/

[23] E. J. Gatwood, J. Pederson, and K. Casey, "Los Angeles district method for prediction of debris yields" U.S. Army Corps of Engineers, Los Angeles District, 2000.

[24] J. H. Pak and J. J. Lee, 'A statistical sediment yield prediction model incorporating the effect of fires and subsequent storm events" J. of the American Water Resources Association, 2008, vol. 44, no. 3, p. 689-699.

[25] H. Fathizad, H. Karimi and S. M. Alibakhshi, "The estimation of erosion and sediment by using the RUSLE model and RS and GIS techniques (case study: Arid and Semi-arid regions of Doviraj, llam province, Iran)". International J. of Agriulture and Crop Sciences. , 2014, 7(6): 304 -314. Online at www.ijagcs.com.

[26] United State Society of Dam (USSD), "Modeling Sediment Movement in Reservoirs". Report prepared by the USSD Committee on Hydraulics of Dams, Subcommittee on Reservoir Sedimentation, 2014.

[27] A. Walkle and I. A. Black, "An examination of the Degtjarett method for determining soil organic matter and proposed modification of the chromic acid titration method" Soil Sci. , 1934, 37: $29-38$.

[28] I. Y. Y. Mallo, and L. L. O. Mgbanyi, "Assessment of soil wash and soil erodibility indices on miniature badlands at Gada Biyu, Abuja, Federal Capital Territory, Nigeria". Ethiopian J. of Environmental Studies and Management, 2013, 6(2): $135-142$.

[29] C. Pieri, "Fertility of soils: A future for farming in the West Africa Savannah". Springer-Verlag, Berlin, 1991.

[30] A. K. Mukhi, "Erodibility of some vertisols". J. Ind. Soc. Sci. 1988, 36: $532-535$

[31] G. H. Bouyoucos, "Method of determining particle sizes by the soil hydrometer". Agron. J. , 1951, 43: $434-438$.

[32] R. B. Painter, "Sediment, In Rodda", J. C. (ed.) 1976: Facets in Hydrology. London: John Wiley \& Sons., 1976, pp. 163198.

[33] R. I. Ferguson, "Hydraulic and sedimentary controls of channel pattern". In: Richard, K.S. (ed)., River Channels; Environment and Process. Oxford: Blackwell, 1987, pp 12958.

[34] R. I. Straud, "Bureau of reclamation procedure for predicting sediment yield, in present and prospective technology from predicting sediment yield and sources". Proceeding of the sediment yield workshop, USDA sediment Lab., Oxford, Mississipi, $28^{\text {th }}-30$ th Nov. 1975

[35] J. R. Gray and F. J. M. Simoes, "Estimating sediment discharge". 690-003-2pass-BMM-r02.indd., 2008. 
[36] G. D. Glysson, "Sediment-transport curves." Open-File Report 87-218, U.S. Geological Survey, Reston, Va., 1987, _http:// pubs.er.usgs.gov/pubs/ofr/ofr87201> (Oct. 6, 2005).

[37] K. G. Renard, G. R. Foster, G. A. Weesies, D. K. McCool and D. C. Yoder, "Predicting soil erosion by water". Agriculture Handbook 703, US Department of Agriculture, Agricultural Research Service, Washington DC., 1997.

[38] L. C. Brown and G.R. Foster, "Storm Erosivity Using Idealized Intensity Distributions," Transactions of the American Society of Agricultuml Engineers, 1987, vol. 30, no. 2, pp. 379- 386.

[39] P. Panagos, C. Ballabio, P. Borrelli, K. Meusburger, A. Klikc, S. Rousseva, M. Percec Tadi'c., S. Michaelides, M. Hrabalíková, P. Olsen, J. Aalto, M. Lakatos, A. Rymszewicz, A. Dumitrescu, S. Beguería and C. Alewell, "Rainfall erosivity in Europe". Sci. Total Environ, 2015, (511): 801814.

[40] S. Vemu and U. B., Pinnamaneni, "Sediment Yield estimation and prioritization of watershed using remote sensing and GIS”, International Archives of the Photogrammetry, Remote Sensing and Spatial Information Sciences, 2012.
[41] D. K. McCool, L. C. Brown and G. R. Foster, "Revised slope steepness factor for the universal soil loss equation", Trans Am Soc. Agric. Eng, 1987, 30:1387-1396.

[42] J. M. van der Knijff, R. J. A. Jones and L. Montanarella, "Soil erosion risk assessment in Europe", EUR 19044 EN. Luxembourg: European Commission, Joint Research Centre, 2000.

[43] D. M. Hicks, J. Hill and U. Shankar, "Variation of suspended sediment yields around New Zealand: the relative importance of rainfall and geology". In: Erosion and Sediment Yield: Global and Regional Perspectives (ed. by D. E. Walling \& B. W. Webb) (Proc. Exeter Symposium, July 1996), 149-156. IAHS Publ. 236. IAHS Press, Wallingford, UK.

[44] D. M. Hicks and U. Shankar, "Sediment from New Zealand rivers". NIWA Chart, Misc. Series no. 79. National Institute of Water and Atmospheric Research, Wellington, New Zealand, 2003.

[45] J. E. Gartner, S.H. Cannon, and D.R. Helsel, "Multivariate statistical models for predicting potential sediment yields from Southern California watersheds": U.S. Geological Survey Open-File Report 2009-1200, 2008. 